\title{
Analysis of Signal-Averaged Electrocardiogram Performance for Body Surface Recordings
}

\author{
Nolwenn Tan ${ }^{1}$, Laura Bear ${ }^{1}$, Mark Potse ${ }^{1,2,3}$, Stéphane Puyo ${ }^{1}$, Marianna Meo ${ }^{1}$, Rémi Dubois ${ }^{1}$ \\ ${ }^{1}$ Institute of Electrophysiology and Heart Modeling (IHU Liryc), Foundation Bordeaux University, \\ Pessac-Bordeaux, France \\ ${ }^{2}$ CARMEN Research Team, Inria Bordeaux Sud-Ouest, Talence, France \\ ${ }^{3}$ Univ. Bordeaux, IMB, UMR 5251, Talence, France
}

\begin{abstract}
To test the performance of signal averaging on body surface electrocardiograms (SAECG), a comparative analysis of four sources of perturbation, 1) uncorrelated noise, 2) beat alignment, 3) physiological variability and 4) respiratory movement was performed. The first two cases were assessed using a computer model of a ventricular beat. The other two cases were tested using high resolution body surface signals recorded from a torso tank $(N=2)$ and patient data $(N=4)$ respectively. In the first case, SAECG successfully removed a high level of noise made up of white Gaussian noise (WGN) with $\sigma=10 \mu \mathrm{V}$ and $50 \mathrm{~Hz}$ noise with a signal to noise ratio (SNR) of $9 \mathrm{~dB}$ since the root mean square error of the noise (RMSE $\left.E_{\text {noise }}\right)$ was $0.65 \pm 0.01 \mu \mathrm{V}$ and $1.30 \pm 0.01 \mu \mathrm{V}$, respectively. The RMSE of the averaged QRS (RMSE $E_{S A Q R S}$ ) was slightly changed by physiological variability $\left(R M S E_{S A Q R S}=\right.$ $4.18 \pm 1.38 \mu \mathrm{V}$ ) when comparing the $S A_{Q R S}$ resulting from the average of 100 different beats taken from the same recording. While $S A_{Q R S}$ are distorted by respiration artefacts, the beats selected during the exhalation phase produced the least distortion to the SA $A_{Q R S}$ with a $R M S E_{S A Q R S}=16.28 \pm 12.58 \mu \mathrm{V}$. To conclude, SAECG can efficiently de-noise signals in presence of uncorrelated noise without distorting the $S A_{Q R S}$. However, respiration motion introduces amplitude shift between $S A_{Q R S .}$
\end{abstract}

\section{Introduction}

Signal averaging of an ECG (SAECG) is a non-invasive technique to reduce noise or increase the signal to noise ratio (SNR) without the distorting effects of filtering on the QRS [1]. This technique is mostly used in the detection of low amplitude signals called "late potentials" [2], [3], [4], markers for sustained ventricular arrhythmias embedded in the QRS but usually hidden by skeletal muscle activity and by external noise localized at the end of the QRS. The SAECG is also used to evaluate the risk for atrial fibrillation focusing on prolonged $\mathrm{P}$ wave [5] and for noninvasive electrocardiographic imaging [6].

Another potential application is the detection of His bundle activation from body surface signals [7]. However the very small potential associated to the His bundle activity combined with residual noise make this detection very challenging.

A high efficiency of SAECG to de-noise electrocardiograms (ECG) is imperative to identify low amplitude variations of ECG in part responsible for some arrhythmias. In this study, we aim to report the performance of SAECG in terms of noise reduction and $\mathrm{SA}_{\mathrm{QRS}}$ modification testing various sources of signal perturbation, with the goal of setting an optimal workflow for future studies.

\section{Materials and methods}

\subsection{Datasets}

Three datasets were used to accomplish this study.

(i) A computer model $(\mathrm{N}=1)$ from a torso model with 252 body surface recordings at $1000 \mathrm{~Hz}$ [8] composed of a ventricular beat duplicated into multiple beats equally spaced $(\mathrm{RR}$ interval $=909 \mathrm{~ms}(66 \mathrm{bpm}))$ or randomly spaced (RR interval $=800+/-59 \mathrm{~ms}(75 \mathrm{bpm})$ ). (ii) 5minutes of experimental data $(\mathrm{N}=2$, sinus rhythm and left ventricular pacing) obtained from a torso tank with 256 surface signals recorded at $2048 \mathrm{~Hz}$ simultaneously with 108 epicardial signals from a pig heart suspended inside and (iii) clinical data $(\mathrm{N}=4)$ composed of 128 body surface signals and breathing signal recorded simultaneously from a respiratory belt at $2048 \mathrm{~Hz}$ were used.

\subsection{Comparisons methods}


The efficacy of SAECG was assessed using 3 metrics:

1- the RMSE of noise (RMSE ${ }_{\text {noise }}$ ) based on the average of the squared differences between a signal without noise $\left(\right.$ RMSE $\left._{\text {noise }}=0\right)$ and the noise measured over an interval of $50 \mathrm{~ms}$ during the ST segment;

2- the RMSE of the SAQRS (RMSE $E_{S A Q R S}$ ) that measures the root mean square error between the " $\mathrm{SA} \mathrm{Q}_{\mathrm{QRS}}$ gold

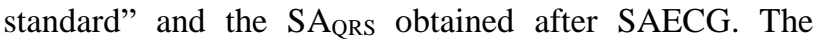
"SA $A_{Q R S}$ gold standard" chosen is detailed for each case in Section 2.3;

3- the correlation coefficient of the SAQRS

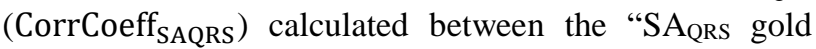
standard" and the SAQRS obtained after SAECG.

The results presented for these 3 metrics were computed from beat averaging for all the recorded leads. The mean of all the averaged leads was computed (252 channels for the computing model, 256 channels, for the experimental data, and 128 channels for the clinical data) and then the mean over the $\mathrm{N}$ sets of data available was calculated. For the experimental data $\mathrm{N}=2$, for the clinical data $\mathrm{N}=4$ and for the computer model $\mathrm{N}=15$ as 15 random choices of 200 consecutives beats were used to compute the mean Variables were reported as mean $\pm \mathrm{SD}$.

\subsection{Methods}

The first step of SAECG was the creation of a virtual lead and a virtual template used for beat detection and alignment using a principal component analysis (PCA) [9]. PCA is a dimension-reduction technique used to reduce a large set of correlated variables to a smaller set of linearly uncorrelated variables called principal components. The first principal component contains the largest variance and was used in this study. The virtual template is compared with each beat of the virtual lead, by cross correlation. The positions for the alignment were determined as the position where the cross correlation was maximal. Finally beat averaging was performed over all recorded and aligned beats for each lead. Each case was processed using SAECG with or without signal processing tools (notch filter, band pass filter (BPF), baseline removal) to finally compute the three metrics presented in Section 2.2 (Figure 1). Signal processing algorithms were developed using Matlab (2015Rb).

Four sources of perturbation were analyzed to study the performance of SAECG.

\section{Case 1: additive noise}

To study the efficiency of SAECG to remove noise, a WGN $(\sigma=10 \mu \mathrm{V})$ was added to the simulated data (RR interval constant) and independently a $50 \mathrm{~Hz}$ noise with a SNR of $9 \mathrm{~dB}$ was added (RR interval non constant). For the latter, the use and performance of a notch filter was analyzed. The alignment was perfect as the known positions of each ventricular beat was used for averaging.
The RMSE $E_{S A Q R S}$ and the CorrCoeff SAQRS $_{\text {were computed }}$ between the $\mathrm{SA}_{\mathrm{QRS}}$ (gold standard) without any noise.

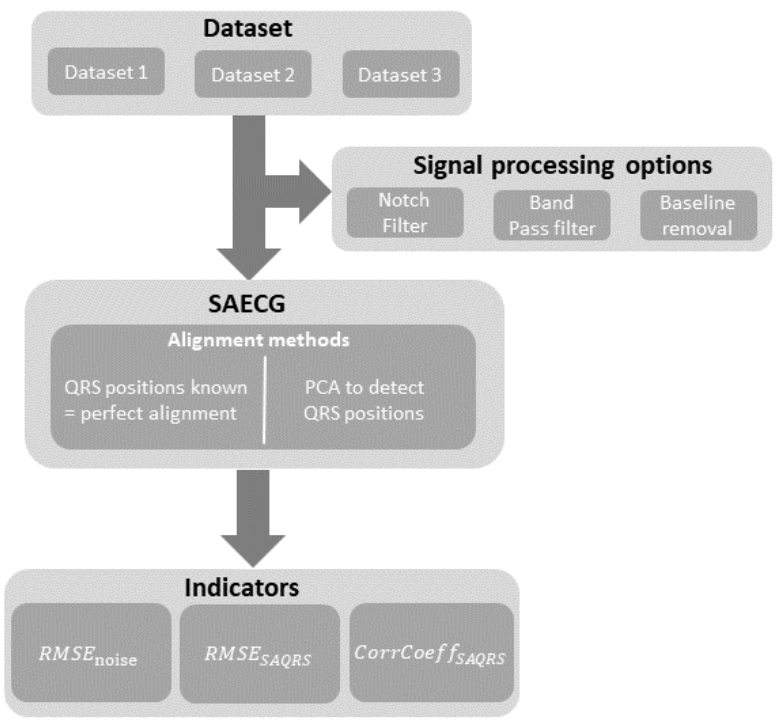

Figure 1: Workflow to test the SAECG performance. For each dataset signal processing methods can be applied independently, combined with each other or not used. Then SAECG is performed for each dataset using perfect alignment for case 1 and case 3 while QRS detection and alignment are determined with PCA method for case 2 and case 4 . Finally, the three metrics can be computed.

\section{Case 2: alignment perturbation}

To study the effect of a bad alignment on the $\mathrm{SA}_{\mathrm{QRS}}$, a 50 $\mathrm{Hz}$ noise with a SNR of $9 \mathrm{~dB}$, a WGN $(\sigma=30 \mu \mathrm{V})$ and baseline noise (created by fitting a spline to a patient dataset) were added to the simulated data (RR interval non constant). The use and performance of a notch filter and a $\mathrm{BPF}$ at $0.01 \mathrm{~Hz}$ to $30 \mathrm{~Hz}$ were compared. The RMSE $\mathrm{SAQRS}_{\mathrm{S}}$

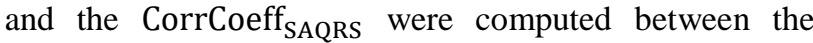
$\mathrm{SA}_{\mathrm{QRS}}$ obtained from dataset 1 after adding the different noises exposed previously 1) based on the average of perfectly aligned beats ( $\mathrm{SA}_{\mathrm{QRS}}$ gold standard) and 2) the $\mathrm{SA}_{\mathrm{QRS}}$ based on PCA to set the positions of the beats ( $\mathrm{SA}$ QRS observed).

\section{Case 3: physiologic variability}

To study the impact of physiological variability on the $\mathrm{SA}_{\mathrm{QRS}}$ using the experimental data, electrograms from a sock, because of the sharper QRS complex recorded, were used to set the QRS positions and to avoid any misalignment. To eliminate noise a notch filter with a band frequency of $1 \mathrm{~Hz}$ and baseline removal were applied. $\mathrm{SA}_{\mathrm{QRS}}$ from five subsequences (100 beats each) of recording from dataset 2 were compared with each other (10 comparisons in total) to evaluate the variability of the $\mathrm{SA}_{\mathrm{QRS}}$ as explained in Figure 2. 


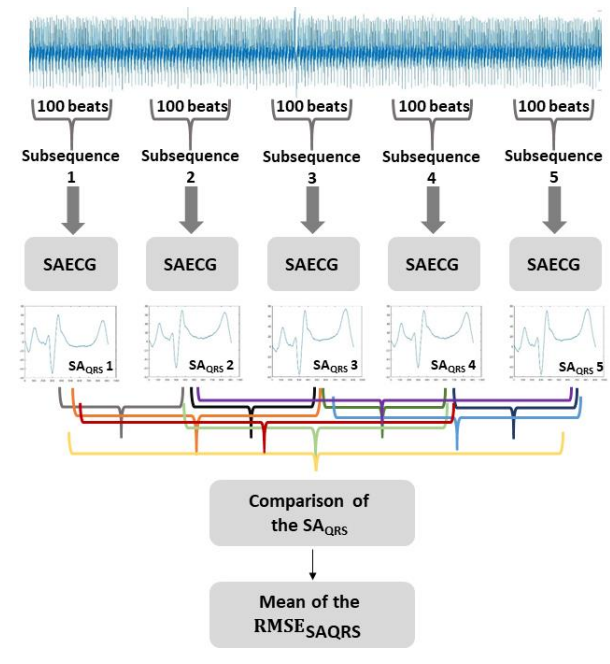

Figure 2: Workflow to compute the RMSE $E_{S A Q R S}$ for the physiological variability and the respiration motion study (for the latter case only three comparisons were performed).

\section{Case 4: respiratory artefacts}

To study the impact of respiration on the $\mathrm{SA}_{\mathrm{QRS}}$ using the clinical data, three scenarios were compared: 1) only the beats in the exhalation respiratory phase were averaged, 2) only the beats during the inhalation respiratory phase were averaged, and 3) all the beats were averaged independently of the respiration. Baseline removal was used as a processing step. Three $\mathrm{SA}_{\mathrm{QRS}}$ made from the average of 100 beats each along the same recording were compared with each other ( 3 comparisons in total) to evaluate the variability of the $\mathrm{SA} \mathrm{QRS}_{\mathrm{Q}}$.

\section{Results}

\section{Case 1: additive noise}

Adding a WGN with $\sigma=10 \mu \mathrm{V}$ to the recording shows that after SAECG, RMSE $E_{\text {noise }}$ decreases as expected in $\frac{\sigma}{\sqrt{N_{\text {beats }}}}$ since $\operatorname{RMSE}_{\text {noise }}=0.65+0.01 \mu \mathrm{V}$ with a number of averaged beats equals to 200 . In the presence of a $50 \mathrm{~Hz}$ noise (SNR $=9 \mathrm{~dB}$ ) the use of a notch filter with a band frequency $(\mathrm{BF})$ of $1 \mathrm{~Hz}$ reduced highly the noise in the signal $\left(\mathrm{RMSE}_{\text {noise }}=1.30 \pm 0.01 \mu \mathrm{V}\right.$ with notch filter vs $2.40 \pm 1.70 \mu \mathrm{V}$ without notch filter), with a minimal distortion of the $\mathrm{SA}_{\mathrm{QRS}}$ in terms of amplitude though the difference without notch filter was around half the RMSE $_{S A Q R S}$ value while using a notch filter $\left(\mathrm{RMSE}_{\mathrm{SAQRS}}=1.43 \pm 0.00 \mu \mathrm{V}\right.$ with notch filter vs $2.30 \pm 1.67 \mu \mathrm{V}$ without notch filter).

Our results also demonstrated that it is better to use a notch filter when the SNR of a $50 \mathrm{~Hz}$ noise is lower than $19 \mathrm{~dB}$. However with higher SNR, the use of a notch filter is not necessary. Moreover these results are valid for 200 averaged beats. To conclude, $50 \mathrm{~Hz}$ and WGN noises can easily be removed by SAECG.

\section{Case 2: alignment perturbation}

Using a BPF was better than a notch filter to reduce noise $\left(\mathrm{RMSE}_{\text {noise }}=1.41 \pm 0.01 \mu \mathrm{V}\right.$ vs $\left.3.08 \pm 0.5 \mu \mathrm{V}\right)$. While the

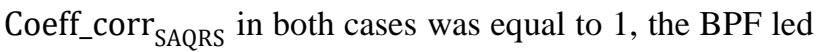
to a smaller RMSE $E_{S A Q R S}$ than the notch filter $\left(\operatorname{RMSE}_{\mathrm{SAQRS}}=0.51 \pm 0.20 \mu \mathrm{V} \quad\right.$ vs $\quad \mathrm{RMSE}_{\mathrm{SAQRS}}=$ $2.15 \pm 1.00 \mu \mathrm{V}$ ). As the levels of noise in case 1 (beat alignment is perfect) and case 2 are about the same range, we can conclude that potential misalignment was corrected through the use of filters (notch filter, BPF) and SAECG.

\begin{tabular}{|c|c|c|c|c|c|c|}
\hline & \multicolumn{2}{|c|}{$\begin{array}{c}\text { RMSE }_{\text {noise }} \\
(\mu \mathrm{V})\end{array}$} & \multicolumn{2}{|c|}{$\begin{array}{c}\text { RMSE }_{\mathbf{Q R S}} \\
(\boldsymbol{\mu V})\end{array}$} & \multicolumn{2}{|c|}{ CorrCoeff $_{\mathrm{QRS}}$} \\
\hline & $\begin{array}{c}\text { Before } \\
\text { SAECG }\end{array}$ & $\mathrm{SA}_{\mathrm{QRS}}$ & $\begin{array}{l}\text { Before } \\
\text { SAECG }\end{array}$ & $\mathrm{SA}_{\mathrm{QRS}}$ & $\begin{array}{c}\text { Before } \\
\text { SAECG }\end{array}$ & $\mathrm{SA}_{\mathrm{QRS}}$ \\
\hline $\begin{array}{c}\text { WGN }(\sigma=10 \\
\mu \mathrm{V})\end{array}$ & $\begin{array}{c}9.23 \\
\pm 0.06\end{array}$ & $\begin{array}{c}0.65 \\
\pm 0.01\end{array}$ & $\begin{array}{r}9.99 \\
\pm 0.2\end{array}$ & $\begin{array}{c}0.71 \\
\pm 0.00\end{array}$ & $\begin{array}{c}0.99 \\
\pm 0.00\end{array}$ & $\begin{array}{c}1.00 \\
\pm 0.00\end{array}$ \\
\hline $\begin{array}{c}50 \mathrm{HZ} \\
\text { (SNR=9dB) no } \\
\text { notch filter) }\end{array}$ & $\begin{array}{c}56.24 \\
\pm 12.65\end{array}$ & $\begin{array}{c}2.40 \\
\pm 1.70\end{array}$ & $\begin{array}{r}42.43 \\
\pm 0.01\end{array}$ & $\begin{array}{c}2.30 \\
\pm 1.67\end{array}$ & $\begin{array}{c}0.94 \\
\pm 0.00\end{array}$ & $\begin{array}{c}1.00 \\
\pm 0.00\end{array}$ \\
\hline $\begin{array}{c}50 \mathrm{HZ} \\
(\mathrm{SNR}=9 \mathrm{~dB}, \\
\text { notch filter BF } \\
=1)\end{array}$ & $\begin{array}{r}16.21 \\
\pm 6.49\end{array}$ & $\begin{array}{c}1.30 \\
\pm 0.01\end{array}$ & $\begin{array}{c}2.87 \\
\pm 0.29\end{array}$ & $\begin{array}{c}1.43 \\
\pm 0.00\end{array}$ & $\begin{array}{c}1.00 \\
\pm 0.00\end{array}$ & $\begin{array}{c}1.00 \\
\pm 0.00\end{array}$ \\
\hline $\begin{array}{c}\text { WGN }+50 \mathrm{HZ}+ \\
\text { BL (notch filter } \\
\text { BF =1) }\end{array}$ & $\begin{array}{l}38.21 \\
\pm 8.07\end{array}$ & $\begin{array}{l}3.08 \\
\pm 0.5\end{array}$ & $\begin{array}{l}40.73 \\
\pm 8.44\end{array}$ & $\begin{array}{c}2.15 \\
\pm 1.00\end{array}$ & $\begin{array}{c}0.93 \\
\pm 0.00\end{array}$ & $\begin{array}{c}1.00 \\
\pm 0.00\end{array}$ \\
\hline $\begin{array}{c}\text { WGN + 50HZ + } \\
\text { BL }(\text { BPF }[0.01 \\
30] \text { Hz) }\end{array}$ & $\begin{array}{c}9.03 \\
\pm 0.30\end{array}$ & $\begin{array}{c}1.41 \\
\pm 0.01\end{array}$ & $\begin{array}{l}12.66 \\
\pm 1.35\end{array}$ & $\begin{array}{c}0.51 \\
\pm 0.20\end{array}$ & $\begin{array}{c}0.96 \\
\pm 0.00\end{array}$ & $\begin{array}{c}1.00 \\
\pm 0.00\end{array}$ \\
\hline $\begin{array}{l}\text { Physiologic } \\
\text { variability }\end{array}$ & $\begin{array}{c}6.84 \\
\pm 1.23\end{array}$ & $\begin{array}{c}1.30 \\
\pm 0.68\end{array}$ & $\begin{array}{r}12.89 \\
\pm 2.94\end{array}$ & $\begin{array}{c}4.18 \\
\pm 1.38\end{array}$ & $\begin{array}{c}0.87 \\
\pm 0.03\end{array}$ & $\begin{array}{c}0.98 \\
\pm 0.01\end{array}$ \\
\hline $\begin{array}{c}\text { Exhalation } \\
\text { respiratory } \\
\text { phase }\end{array}$ & $\begin{array}{c}6.85 \\
\pm 2.95\end{array}$ & $\begin{array}{c}1.88 \\
\pm 1.23\end{array}$ & $\begin{array}{c}38.59 \\
\pm 16.00\end{array}$ & $\begin{array}{c}16.28 \\
\pm 12.58\end{array}$ & $\begin{array}{c}0.95 \\
\pm 0.06\end{array}$ & $\begin{array}{c}0.99 \\
\pm 0.01\end{array}$ \\
\hline $\begin{array}{l}\text { Inhalation } \\
\text { respiratory } \\
\text { phase }\end{array}$ & $\begin{array}{c}6.89 \\
\pm 2.70\end{array}$ & $\begin{array}{c}1.95 \\
\pm 1.25\end{array}$ & $\begin{array}{c}60.12 \\
\pm 51.14\end{array}$ & $\begin{array}{c}18.69 \\
\pm 14.60\end{array}$ & $\begin{array}{c}0.93 \\
\pm 0.04\end{array}$ & $\begin{array}{c}0.99 \\
\pm 0.01\end{array}$ \\
\hline $\begin{array}{l}\text { No phase } \\
\text { selected }\end{array}$ & $\begin{array}{c}7.70 \\
\pm 3.10\end{array}$ & $\begin{array}{c}1.97 \\
\pm 1.20\end{array}$ & $\begin{array}{c}47.27 \\
\pm 23.88\end{array}$ & $\begin{array}{c}19.21 \\
\pm 16.54\end{array}$ & $\begin{array}{c}0.94 \\
\pm 0.06\end{array}$ & $\begin{array}{c}0.99 \\
\pm 0.01\end{array}$ \\
\hline
\end{tabular}

Table 1: Table summary of the results

\begin{tabular}{c|c|c|c|}
\multicolumn{1}{c|}{ CASE 1 } & \multicolumn{1}{c}{ CASE 2 } & CASE 4 \\
BF = Band Frequency & BPF = Band Pass filter & WGN = White Gaussian Noise \\
BL = Baseline & SNR = Signal to Noise Ratio
\end{tabular}

\section{Case 3: physiological variability}

Physiological variability has a poor effect on the $\mathrm{SA}_{\mathrm{QRS}}$ correlation coefficient $\left(\right.$ CorrCoeff $\left._{\mathrm{SAQRS}}=0.98 \pm 0.01\right)$ and a minimal impact on the $\mathrm{RMSE}_{\mathrm{SAQRS}}\left(\mathrm{RMSE}_{\mathrm{SAQRS}}=\right.$ $4.18 \pm 1.38 \mathrm{mV}$ ) while averaging 100 beats.

\section{Case 4: respiratory artefacts}

SAECG in different phases of respiration demonstrated that selecting the beats during the exhalation phase produced the least change in the QRS waveforms amplitude (Figure 3A) when compared to the inhalation phase (B) or without any preliminary selection of the beats 
(C). This is quantified by an RMSE $E_{S A Q R S}$ of $16.28 \pm 12.58$ $\mu \mathrm{V}$ compared to $\mathrm{RMSE}_{\mathrm{SAQRS}}=18.69 \pm 14.60 \mu \mathrm{V}$ and $\operatorname{RMSE}_{\mathrm{SAQRS}}=19.21 \pm 16.54 \mu \mathrm{V}$ respectively. However, the correlation coefficient $\left(\right.$ CorrCoeff $\left._{\mathrm{SAQRS}}=0.99 \pm 0.1\right)$ was similar for the three scenarios indicating there is minimal deformation of the QRS waveform.

A

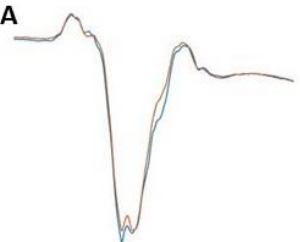

C

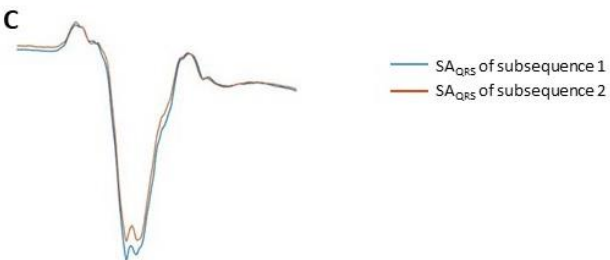

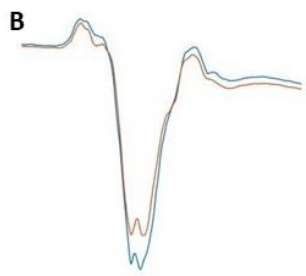

Figure 3: Comparison between two $\mathrm{SA}_{\mathrm{QRS}}$ from two subsequences (100 beats averaged) within the same recording from dataset 3 .

A. $\mathrm{SA}_{\mathrm{QRS}}$ selected during the exhalation respiratory.

B. $S A_{Q R S}$ selected during the inhalation respiratory.

C. $\mathrm{SA}_{\mathrm{QRS}}$ with no preliminary selection of the beats.

\section{Discussion}

The presented results demonstrate that SAECG is a performant technique to remove uncorrelated noise and to reveal the true underlying QRS complex. These results are consistent with previous studies showing the efficiency of SAECG, especially to detect small electrical components as the late potentials.

While the present study has supplied much useful information about the efficiency of SAECG, it has several limitations that must be acknowledged. Firstly, the results of this study could be more accurate using larger and longer experimental and clinical datasets. Finally, the correlation coefficient of the $\mathrm{SA}_{\mathrm{QRS}}$ was computed on the entire $\mathrm{SA}_{\mathrm{QRS}}$ complex leading to correlation coefficient superior to 0.9 in most cases. However, when using SAECG to detect late potentials for instance a very small distortion of the QRS can affect their detection but will not deteriorate the correlation coefficient much. Therefore, the results of this study would have to be interpreted according to each specific application.

\section{Conclusion}

SAECG is a powerful signal processing technique to denoise the ECG without distorting the signals. $50 \mathrm{~Hz}$ noise, WGN and baseline artefacts while using SAECG (coupling to certain filtering process in some cases) are easily removed and $\mathrm{SA} \mathrm{QRS}_{\mathrm{QRS}}$ distortion is minimal. Physiological variability has a weak impact on the $\mathrm{SA}_{\mathrm{QRS}}$ distortion with $\mathrm{SA}_{\mathrm{QRS}}$ using different beats within the same recording showing only very small deformations. On the other hand, the respiratory motion can deteriorate the $\mathrm{SA}_{\mathrm{QRS}}$, but by selecting the beats during the exhalation phase the amplitude shift effects of the $\mathrm{SA}_{\mathrm{QRS}}$ can be reduced.

\section{Acknowledgments}

This work was supported by the French National Research Agency, grant reference ANR-10-IAHU04-LIRYC. This work was granted access to HPC resources of CINES under GENCI allocation 2019-A0050307379.

\section{References}

[1] L. Sörnmo, E. Trägårdh, and M. B. Simson, "The Signal-Averaged Electrocardiogram,” 2010, pp. 17931821.

[2] M. Simson, "Use of Signals in the Terminal Qrs Complex To Identify Patients With VentricularTachycardia After Myocardial-Infarction," Circulation, vol. 64, no. 2, pp. 235-242, 1981.

[3] P. Lander, E. J. Berbari, C. V Rajagopalan, P. Vatterott, and R. Lazzara, "Critical Analysis of the SignalAveraged Electrocardiogram. Improved Identification of Late Potentials.," Circulation, vol. 87, no. 1, pp. 105117, Jan. 1993.

[4] J. A. Gomes et al., "A Comparative Analysis of Signal Averaging of the Surface QRS Complex and Signal Averaging of Intracardiac and Epicardial Recordings in Patients with Ventricular Tachycardia," Pacing Clin. Electrophysiol., vol. 11, no. 3, pp. 271-282, 1988.

[5] J. S. Steinberg, S. Zelenkofske, S. C. Wong, M. Gelernt, R. Sciacca, and E. Menchavez, "Value of the P-Wave Signal-Averaged ECG for Predicting Atrial Fibrillation After Cardiac Surgery.," Circulation, vol. 88, no. 6, pp. 2618-2622, Dec. 1993.

[6] L. R. Bear, et al., "Cardiac Electrical Dyssynchrony is Accurately Detected by Noninvasive Electrocardiographic Imaging," Hear. Rhythm, vol. 15, no. 7, pp. 1058-1069, Jul. 2018.

[7] N. C. Flowers, L. G. HORAN, and W. YANG, “Application of Beat-to-Beat Techniques," Pacing Clin. Electrophysiol., vol. 13, no. 12, pp. 2148-2155, Dec. 1990.

[8] M. Potse, "Scalable and Accurate ECG Simulation for Reaction-Diffusion Models of the Human Heart," Front. Physiol., vol. 9, p. 370, Apr. 2018.

[9] F. Castells, et al., "Principal Component Analysis in ECG Signal Processing," EURASIP J. Adv. Signal Process., vol. 2007, no. 1, p. 074580, Dec. 2007.

Address for correspondence:

Nolwenn TAN

IHU LIRYC, Avenue du Haut-Lévêque, 33604 Pessac, France Nolwenn.tan@ihu-liryc.fr 